\title{
La construcción de los personajes en la obra de Ena Lucía Portela
}

\author{
Characters Construction in Ena Lucia Portela’s Narrative
}

\section{IVONNE SÁNCHEZ BECERRIL}

Universidad Nacional Autónoma de México · ivonne.sb@gmail.com

Maestra en Letras latinoamericanas por la UNAM y especialista en literatura mexicana del siglo XX por la UAM. Profesora de asignatura en la Universidad Autónoma del Estado de Morelos (2011-2012). Miembro asociado del Séminaire Amérique Latine (SAL), de Paris-Sorbonne, donde realizó una estancia de investigación doctoral durante 2013, y miembro fundador del Seminario de Estudios sobre Narrativa Latinoamericana Contemporánea (SENALC) de la UNAM. Actualmente desarrolla su investigación doctoral en Letras (letras latinoamericanas) en la UNAM sobre la metaficción en la novela cubana y mexicana contemporánea.

RECIBIDO: 22 DE ENERO DE 2015

ACEPTADO: 3 DE JUNIO DE 2015

Resumen: El ensayo identifica y analiza las constantes en la construcción de los personajes de la obra narrativa de Ena Lucía Portela (La Habana, 1972) a fin de dilucidar su papel en el proyecto escritural de la autora, así como sus alcances críticos en la representación de la realidad cubana. Para ello se analizan casi en su totalidad los textos publicados por la autora, centrándose particularmente en el protagonista de la novela La sombra del caminante (2001/2006) y destacando la importancia de la intertextualidad y metaficción como estrategias de la configuración de los personajes

Palabras Clave: Ena Lucía Portela, Cuba, metaficción.

\begin{abstract}
The paper identifies and analyzes the constants in the construction of the characters in the narrative of Ena Lucía Portela (Havana, 1972) to elucidate its role in the project scriptural author and his critics achievements in representing Cuban reality. In order to do so the texts published by the author analyzes almost entirely, focusing particularly on the protagonist of the novel TheWalker's Sahdow (2001/2006) and stressing the importance of intertextuality and metafiction as setting strategies characters.
\end{abstract}

Key Words: Ena Lucía Portela, Cuba, matafiction.

DOI: 10.7203/KAM.5.4515 
Ivonne Sánchez Becerril. Los personajes...

Caracterizados por el despliegue de estrategias narrativas, por su pirotecnia verbal y su destreza para ofuscar al lector, los relatos de Ena Lucía Portela (La Habana, 1972) están poblados de personajes sui generis. Parafílicos, fóbicos, misóginos, misántropos, racistas, trastornados, adefesios, esperpentos, zoilos o escritores, son, a decir de Luisa Campuzano (2004: 161), las directrices de la obra porteliana. $\mathrm{Si}$, como afirma Thomas Pavel, «el interés de cada obra surge del hecho de que propone —en función de la época, el subgénero y a veces el genio del autor- una hipótesis sustancial sobre la naturaleza y la organización del mundo» (cursivas del original) (2005: 42), los personajes centrales de estas narraciones condensan y convocan, por su compleja configuración, los elementos centrales de la hipótesis porteliana. Por lo anterior, a partir de su análisis es posible dilucidar la convergencia entre el universo ficticio representado y los procedimientos formales que se utilizan para evocarlo, acceder a la reinvención, más que descripción, que hace la autora de la realidad en su búsqueda por comprenderla (Pavel).

Denominados raros o raras (Campuzano, 2004: 161), freaks (frikis) o amorales (Araújo 2001: 64) por la crítica temprana, estos peculiares personajes se distinguen por su desafío - voluntario o involuntario, consciente o inconsciente- al consenso. Su postulación misma encierra un reto al lector, pues denominarlos "anormales" devela la segregación simbólica a la que éste les somete por separarse del supuesto hegemónico del individuo que conforma una sociedad determinada. Asimismo, la exploración de sus posibilidades de existencia ofrece una mirada de soslayo a las fuerzas sociales a las que son expuestos y cómo éstas ejercen tensiones contrarias sobre ellos. Por ello no es raro que los relatos oscilen entre la instauración del sinsentido, la perpetración de crímenes de diversa índole y el encuentro con la muerte.

El alto grado de metaficcionalidad permite que las narraciones conlleven reflexiones sobre el mundo ficcional que los engloba. Gracias a ello es posible identificar que la voz narrativa y los escritores ficcionales de un par de novelas (Elpájaro: pincel y tinta china y La sombra del caminante) se refieren a los personajes como héroes; pero su heroicidad se constriñe a la realización de nimias proezas. Por ello, a través de un metacomentario en La sombra del caminante, el escritor ficcional Emilio U postula la preferencia por «los héroes que reconocen la futilidad de sus hazañas» (La sombra 195); de esta forma, Portela nos permite vislumbrar una constante en la concepción de sus personajes. Asimismo, la abigarrada intertextualidad que caracteriza la construcción de los personajes elide efectivamente todo reduccionismo y elude visos de determinismo social en su planteamiento. Los héroes portelianos nacen de la superposición de la representación —en multiplicidad semántica— ficcional y factual.

KAMCHATKA 5 JULIO 2015 
Por lo anterior, me parece pertinente esclarecer tanto las constantes en la caracterización y construcción de los personajes, como la detonación de sentido que les aporta su configuración. ${ }^{1}$

\section{Las constantes}

El rasgo más evidente de los personajes portelianos es la marginalidad; sin embargo, las razones de dicha condición en muchas ocasiones son difusas en un primer momento. No es hasta que por medio de diversas analepsis las narraciones revelan los pasados tormentosos de los personajes y se hacen comprensibles los porqués de su exclusión. Los marginaliza la imposibilidad de cumplir, voluntaria o involuntariamente, con las expectativas sociales impuestas sobre ellos.

Muchos de los personajes son jóvenes universitarios, que, no obstante, son considerados una «mancha social» («La urna», 2009:2). Thais («La urna»), Lorenzo y Gabriela (La sombra) son matemáticos; René («La urna») y Camila (El Pájaro), actores, y Julio («La urna»), Antonio Torres, Ernesto («Voces»), Linda y Zeta (Cien botellas), filólogos, como muy probablemente también lo sean Chantal y Danilo («Un loco»). La «gloriosa colina», como es llamado irónicamente el enclave de la Universidad de La Habana, es evocada en diversos relatos. El ejercicio de profesiones diversas tampoco evita la confrontación social, ni la modelo Bibiana (El pájaro) o E («Desnuda»), ni la maestra de baile Gofia, ni el abogado Moisés (Cien botellas), ni el empleado de limpieza apodado la Momia («Al fondo»), tampoco los escritores evitan esta condición. Mucho menos, Fabián (Elpájaro) que es mantenido por su familia o Mercy («Huracán»), a quien le está negada la posibilidad de trabajar.

La decepción que estos personajes representan para el sistema social de la isla, según mi lectura de los textos portelianos, radica en su discrepancia; pero Portela no reduce la divergencia a un rasgo específico. Por el contrario, plantea que la diferencia es intrínseca a la existencia, que tiene múltiples manifestaciones, y que la asunción de esta oposición también es diversa. La puesta en trama de la experiencia de los sujetos que confrontan la hegemonía por preferencias sexuales, pertenencia racial, características físicas, la comisión de un delito, la transgresión a las normas no escritas o la oposición al sentido común son centrales en la obra porteliana. Sus personajes experimentan esta oposición por

\footnotetext{
${ }^{1}$ Tomo en consideración para la búsqueda de constantes: «La urna y el nombre (un cuento jovial)», «Últimas conquistas de la catapulta fría», «Sombrío despertar del avestruz», «Halleluland», «Un loco dentro del baño», «Voces de muerte sonaron», «Desnuda bajo la lluvia», «Al fondo del cementerio», «Una extraña entre las piedras», «El viejo, el asesino y yo», «Alguna enfermedad muy grave», «Huracán», «En vísperas del accidente» y «El sueño secreto de Cenicienta». Excluyo «Dos almas nadando en una pecera» y «Como si el ojo gris» (inédito) por la dificultad, casi imposibilidad, de localizarlos, y, por el momento, «Todas las palabras» y «La última pasajera». Asimismo, postergo la inclusión en este análisis de Djuna y Daniel.
} 
diversas vías. Unos la asumen sin conflictos; otros inclusive exploran las pulsiones «oscuras» de la naturaleza humana. Por ejemplo, Danilo y el adefesio («Un loco dentro del baño») se enfrentan burlona e irónicamente a la representación de la cordura, cuando ésta descubre al bibliotecario masturbándose en el baño de mujeres en «Un loco dentro del baño»; Lavinia se complace en besar a una cucaracha ante la estupefacción del hombre del aparato para demostrarle que su convivencia con el «enemigo \#1 de las amas de casa y de las personas decentes en general» (2009:16) es familiar en «Al fondo del cementerio»; la modelo E, después de una cansada sesión fotográfica, le muestra al frustrado artista un retrato en el que ella posa desnuda a los siete u ocho años en «Desnuda bajo la lluvia»; Linda en Cien botellas en una pared asume el rechazo de su familia a su homosexualidad como una incomprensión inexplicable aun en personas inteligentes, o el regocijo que pone en su quehacer el zoilo de Hojo Pinta (La sombra). Varios de estos relatos son narrados desde un tono de absurdo o a partir del establecimiento de cierto sinsentido.

La mayoría, en cambio, padece, física y psicológicamente, la diferencia. Se abstraen de la realidad, desarrollan complejos de culpa o inferioridad, o tienen pesadillas. Atraviesan por una serie de facetas que van desde el escarnio, la negación, la culpa, la represión, la simulación, la segregación, a la anulación. Las narraciones de esta escritora impelen al lector a develar los efectos de la violencia, que Slavoj Žižek denomina objetiva, esto es, aquella que es inherente al estado de «normalidad»; constituye el punto de referencia contra el cuál percibimos la perturbación del estado de las cosas — violencia subjetiva一, motivo por el cual se torna invisible (2008: 2$)^{2}$.

La trasgresión de la norma que representan los personajes portelianos es percibida como una violencia subjetiva por parte de los personajes que han interiorizado, que se han sometido, a los procesos de la violencia objetiva. De ahí que los protagonistas de «Un loco dentro del baño», «Al fondo del cementerio», «Desnuda bajo la lluvia» o «En vísperas del accidente» epaten al personaje que representa la cordura, al representante de la salud pública, al fotógrafo frustrado o a una amante mojigata, respectivamente. Es porque representan un peligro para la idea del orden que las familias de Fabián ( $E l$ pájaro) o la de Linda (El pájaro) se distancian de ellos; que Laura («Sombrío despertar») prefiere negar o reprimir su experiencia homoerótica; que Gabriela y Lorenzo son la vergüenza del coronel Lafita/Mayo. Si recurrimos a los planteamientos de Zygmunt Bauman para hacer una interpretación de los personajes

\footnotetext{
2 «However, objetive violence is precisely the violence inherent to this "normal” state of things. Objective violence is invisible since it sustains the very zero-level standard against which we perceive something as subjectively violent. [...] It may be invisible, but it has to be taken of account if one is to make sense of what otherwise seem to be «irrational» explosions of subjective violence.» (2008: 2 )
} 
Ivonne Sánchez Becerril. Los personajes...

portelianos, estos representarían un «punto de reunión de riesgos y temores que acompañan el espacio cognitivo $^{3}$. Son el epítome del caos que el espacio social intenta empeñosamente, aunque en vano, sustituir por el orden, y de la poca confiabilidad de las reglas en las que se ha invertido la esperanza de lograr esta sustitución» (2006: 185).

Los planteamientos de Žižek en torno a la violencia y los de Bauman sobre el funcionamiento de las sociedades modernas se tocan. El sociólogo polaco señala que las dinámicas sociales producen dos fuerzas, una de inclusión —antropofágica - y otra de exclusión —antropoémica一 - La primera impele a los sujetos a integrarse; la segunda, los expele, los aparta para no poner en peligro el orden social. La negación o represión de las preferencias sexuales de Laura en «Sombrío despertar del avestruz» la asemejan; la necesidad de «una mujer de la casa» de Fabián (Elpájaro), o la simulación de normalidad de Lorenzo/Gabriela, constituyen un afán de integración, en un deseo de «equipararse a la mayoría», de «Asimilarse al average man, al "tipo medio" de las estadísticas con sus mismas fantasías, supersticiones y temores, con sus mismos dioses», aún mediante la estrategia del «simulacro, [e]l mimetismo protector» (La sombra 32).

Estas tensiones actúan tanto de manera interna como externa al individuo mediante el ejercicio de violencia objetiva, simbólica —encarnada en el lenguaje y sus formas, así como en la imposición de significados (Žižek, 2008:1-2) - y sistémica —consecuencia del funcionamiento de los sistemas políticos y económicos (2)- En La sombra del caminante, el narrador cede la voz a la interiorización del actuar de estas fuerzas:

Si usted es cuerdo - y nosotros le creemos por que usted así lo afirma-, usted sabe que asesinar al prójimo es de mala educación. Sabe que es un acto vulgar, prosaico, grosero y cavernícola. Si por alguna falla en su cordura usted ignorase lo anterior, al menos debe saber qué les espera a los que asesinan sin pedir permiso a las autoridades competentes. Debe saber cómo acaban sus días los que asesinan, así, al descaro, al garete, por la libre. En nuestro país se aplica la pena de muerte y a mucha honra. Expulse, pues, de su mente esos sentimientos y deseos incorrectos como diablillos de cola torcida. Repudie ese incitante cosquilleo que le recorre todo el cuerpo y lo acaricia por dentro. Aplaste esas mariposas

\footnotetext{
${ }^{3}$ Z. Bauman señala que el espacio social debe verse como «una interacción compleja de tres procesos entrelazados, aunque distinto -“espaciamientos" cognitivos, estéticos y morales-» (2006: 167), en el que el espacio cognitivo es el relativo al manejo de las distancias conforme al manejo de conocimiento; el estético, un espacio es aquel en el que se da el disfrute; el moral, aquel vinculado con el establecimiento de la responsabilidad del «ser para» el Otro, como rostro, es decir despojado de la máscara etimológica de la palabra persona. Los espacios cognitivos y estéticos son susceptibles de administración y en los proyectos de la modernidad inhiben el espacio moral, pues este los amenaza.
} 
Ivonne Sánchez Becerril. Los personajes...

dañinas que lo asaltan de vez en cuando y no lo dejan dormir. En una palabra: reprímase. [las negritas son mías] (Portela 2006:17).

Los saberes adquiridos sobre el «correcto» funcionamiento del mundo, sobre la norma que mantiene el orden social, coaccionan a los personajes a la evasión, el ensimismamiento, la angustia o la proscripción.

Las noches de muchos de los personajes de Portela están pobladas por pesadillas; los días, de angustias. Lavinia («Al fondo»), una chica de «fealdad tísica» (2009:19), se «adivinaba diestra a la hora de inspirarla [repugnancia] a los demás» (19); esta «habilidad» la llena por momentos de regocijo, pero en otros, «la sumía en pozos de melancolía, ese cae y cae el desapego del ser para consigo mismo. La entregaba al deseo de asimilarse a las piedras, a las losas rotas, a los vanos conjuntos de mármol o de bronce» del cementerio vecino (19). Y entonces empezaban las pesadillas, «sueños horribles que acaban en aullidos» que la hacían revolcarse «entre las sábanas como una cucaracha mal ejecutada» (20) en las que la atormentan los posibles motivos de la desaparición — que se insinúa forzada- de sus padres. En cambio las pesadillas de Lorenzo Lafita (La sombra del caminante), un hombre de «proporciones aúreas», perfecto, son «noches se sima, descenso, báratro, orco, antenora, infierno recurrente» en las que sostiene una tortuosa batalla kafkiana consigo mismo (2006:57); sus pesadillas encierran la amenaza de ser juzgado por traición a la patria, como lo indica la especificidad dantesca del antenora. Esta continua tensión entre «los abismos de afuera (angustia) y los de adentro (desesperación)» («Al fondo» 2009:11) convierten a los personajes en niños-viejos, muchachos, como Lisandro «que si bien no llegaba a los veinte, en verdad parecía un anciano» (11) o como Lorenzo, que semeja a «Lao-tsé, viejo y niño a la vez, un cincuentón, honorable y rígido en el estilo de Marco Junio Bruto» (La sombra 2006:104), un chico que «A los diecinueve casi veinte, es un hombre todo pretérito» (78).

Odette Casamayor Cisneros ha subrayado que, ante el caos que impera socialmente -siempre sólo trasfondo de las narraciones—, «los personajes de Portela han optado por permanecer ingrávidos: es decir inertes, indiferentes ante la sensación de caos» (2009:3); ha caracterizado abstracción como desapego, displicencia, dejadez, y su risa como vacía, provista de un «humor cool». Y aunque, en efecto, como esta investigadora señala, «los personajes se ríen de su propia impotencia frente a lo social y de su insignificancia en medio del caos contemporáneo» (6) el ensimismamiento, por ejemplo, de «nuestro héroe» en La sombra del caminante poco tiene que ver con la indolencia; ni la risa cándida de Zeta (Cien 
Ivonne Sánchez Becerril. Los personajes...

botellas en una pared) deja de tener relación y contraparte con su especie de mantra protector, la canción «Cien botellas en una pared».

Si Lorenzo «Solía limitarse con soberano empeño a los jardines colgantes de Babilonia y a las esferas inmóviles del hiperuranios, a la luna de Valencia y a otras lunas de menor cuantía.» (La sombra 2006:105) y al «igual que en otros temas grandiosos como los huecos de la capa de ozono, la legislación sobre la eutanasia o la guerra de Cisjordania, carecía de opinión» (190) es parte de un complejo proceso de autocriminalización, en el que se abstrae en su angustia. En cambio, el complejo personaje de Zeta no solo se ríe por «guanajería», también se paraliza de miedo: «supe cómo es que el miedo sustituye al dolor, cómo lo eclipsa y enrarece en circunstancias de extremo peligro» (Cien botellas 2002:19), y huye de toda confrontación o resolución, por ejemplo cuando evade la toma de decisión con respecto a la incompatibilidad de su relación con Moisés y el desarrollo de su embarazo. Zeta ríe (¿nerviosamente?) ante lo que le parece absurdo — v.g. que a Yadelis le parezca «bonito» Pancholo—, ante lo inexplicable de los complejos ajenos - las misteriosas diatribas de Moisés-, o para evadir la confrontación directa. Y entonces su risa ofusca, desarma, inquieta a los otros: «me río por pura guanajería, porque estoy contenta, y la gente cree que me burlo. O digo algo que, cualquier insignificancia, cualquier cosita, y la gente cree que ironizo ¿Por qué lo creen? No sé. El hecho es que se acomplejan.» ( 54).

Si estos comportamientos permiten a los personajes sobrevivir en el orden social, asimilarse, cuando las tensiones antropoémicas predominan, llega el rechazo, el sacrificio (chivos expiatorios, pharmakos) o la proscripción. Se forman puntos de segregación que a veces son también de encuentro. Lavinia, Lisandro y la Momia habitan una pocilga al fondo del cementerio; Mercy («Huracán») está prácticamente recluida en una casa de El Vedado; Thais, René y Julio se confinan en un departamento con la puerta tapiada, y Lorenzo/Gabriela vagan por «La Habana Profunda» (2006:169) en La sombra del caminante. Sin embargo, «Sabe que nada pueden los proscritos, ya sea juntos o separados, contra la soledad y la fuga» (La sombra 2006:174). No obstante que los personajes en muchas ocasiones establecen pequeñas comunidades ${ }^{4}$ de fuga, los relatos portelianos frecuentemente terminan con la muerte. Por un lado, la narradora de «En vísperas del accidente», «nuestro héroe» y Emilio U dan la muerte; por otro, Fabián (El pájaro), la narradora de «El viejo, el asesino y yo», y la instructora de tiro y su ayudante en La sombra son asesinados; pero los más buscan el suicidio: Mercy («Huracán»), Thais,

\footnotetext{
${ }^{4}$ En estas pequeñas congregaciones se pueden encontrar patrones: triángulos — «pedazo de cantidad mística» («La urna» 2009:8) —, por ejemplo, Thais-René-Julio en «La urna».
} 
Ivonne Sánchez Becerril. Los personajes...

René y Julio («La urna»), Aimée y Lorenzo/Gabriela (La sombra). Solo con la muerte escapan de la ambivalencia (Bauman 2006: 126).

\section{La construcción}

Pese a los sombríos destinos de muchos de los personajes portelianos, las narraciones eluden efectivamente toda afectación del lector, cualquier manipulación mediante el pathos. A través de una saturación semántica y una concepción sui generis de sus protagonistas, Portela sortea no solo el peligro, como advierte Žižek, que conlleva una mirada directa a la violencia, la pérdida de la objetividad en (y de) la reflexión; también evita el reduccionismo, y al mismo tiempo, refuerza la formulación de su hipótesis sustancial de mundo (Pavel).

El protagonismo de los jóvenes en los cuentos y novelas de la escritora habanera nos haría suponer que de alguna forma representan a una generación de cubanos y que ponen en escena las reducidas posibilidades de existencia que tienen en un contexto tan complejo como el de la isla en los años en derredor del cambio de milenio. Una generación que no experimentó «el desencanto», como afirma Jorge Fornet (2006), pero que vivió una «atmósfera psicológica» (Bobes 2000) compleja; una generación «extraviada» como la llama Ángel Santiesteban-Prats (2009) al establecer un símil con la generación perdida norteamericana. Sin embargo, el tono y las estrategias narrativas de los relatos permiten sospechar que busca romper con la explotación de estereotipos de lo cubano sin imponer otros y dar cuenta de algunos de los comportamientos que emergieron o se diversificaron tras el colapso del Bloque Soviético (Bobes 2000: 234). Lo anterior se reafirma cuando del análisis de la obra emerge la certeza de que los personajes no sostienen enteramente las narraciones, sino que en éstas son igualmente importantes el manejo del lenguaje, la construcción del tiempo, el espacio y la trama, así como la historia. De ahí el acierto, la belleza, de los textos (Pavel).

Portela cohíbe la empatía del lector con sus protagonistas mediante un distanciamiento continuo que logra con la puesta en evidencia del artificio narrativo y, por ende, del estatus de personaje de los protagonistas; con una importante carga intertextual que remite constantemente a otros personajes, a otras representaciones de sujeto; con un alto grado de metaficcionalidad en los textos que le permite insertar como metacomentarios instrucciones de lectura o teorizaciones en torno a la concepción de los personajes o su proceso de construcción.

El trato a los personajes centrales de las narraciones porteliana como héroes procede de las propias novelas. En El pájaro: pincel y tinta china Camila refiere a Bibiana el último de los cuentos de la antología Los últimos serán los primeros — doble de la de Salvador Redonet- se refiere a sus 
Ivonne Sánchez Becerril. Los personajes...

protagonistas como héroes, pues asume el tratamiento que les da la voz narrativa de dicho cuento: «el narrador parece convencido de que sus héroes son tremendos tipos que están haciendo la gran cosa» (1999:160). La dislocada voz narrativa de El pájaro se refiere al escritor ficcional Emilio U de la siguiente forma: «Emilio no llevaba la marca de los seres que van a morir temprano, de esos héroes románticos y parecidos a las mariposas.» (235). La denominación se repite en La sombra del caminante, pues la voz narrativa llama «nuestro héroe» a la excepcional criatura dúplex de Lorenzo Lafita y Gabriela Mayo.

Sin embargo, podemos identificar que hay dos ideas de lo heroico que se oponen en ambas novelas. Por un lado, hay una crítica a la heroicidad nacionalista, la que lleva a cabo proezas en nombre de una colectividad. Cuando Camila, en El pájaro, lee en un libro de Historia de Grecia sobre la batalla de las Termópilas, reflexiona, en torno a la ley espartana que indicaba que «ningún guerrero tenía derecho a ceder»: «Pero qué tipos más excéntricos, pensó Camila, cualquiera diría que padecían de tedio crónico. Mala cosa el aburrimiento, a uno le puede dar por volverse heroico.» (258). Asimismo, en La sombra, Emilio, lamenta «Otro héroe por gusto, como todos los héroes.» (cursivas del original) (195) en un contexto narrativo en el que podemos leer entre sus notas de diario la transcripción de la siguiente cita de Schopenhauer: "Honradamente nadie puede decir nada bueno acerca de ningún carácter nacional. Antes bien, lo único que aparece como diferente en cada país es la cortedad de miras, la perversidad y la maldad de los hombres; y a eso se le llama 'carácter nacional' [...]» (cursivas del original) (197). El tipo de héroes que se rigen irreflexivamente por las leyes y demandas nacionalistas se plantean como absurdos en los relatos.

Los héroes portelianos son, como ya referí que los prefiere Emilio U, «héroes que reconocen la futilidad de sus hazañas» (La sombra 2006:195), aquellos cuya modesta proeza es su diferencia, su disidencia de la norma. Una y otra idea de heroicidad se contraponen. La primera está vinculada a una exaltación nacionalista en la que se supedita de forma impulsiva lo individual a lo social, propugna la norma desde la hegemonía; la segunda noción, la que representan los héroes de los relatos estudiados, subraya la confrontación, voluntaria o involuntaria, consciente o inconsciente, del individuo con el orden social. Por ello en la reflexión que Emilio hace en torno al carácter absurdo de los primeros y su preferencia por los segundos, se lamenta: «Los héroes están fatigados. Desgraciada la tierra que necesita héroes. Desgraciada la tierra que necesita. Desgraciada la tierra. Desgraciada.» (cursivas del original) (195). 
Los héroes portelianos, influenciados por la tradición clásica, se dividen en cómicos y trágicos; los primeros, como describe Aristóteles en su Poética ${ }^{5}$, representan peores de lo que son a los hombres reales y, a los segundos, mejores. Los primeros tienden al empleo de la burla, de la farsa, la parodia, el escarnio, la jovialidad; los segundos son «esforzados», hermosos, severos, infaustos de tonos grandilocuentes e imposibilitados para comprender la risa. En las narraciones de Portela con frecuencia aparecen ambos y conviven, a veces en conflicto, dentro de un mismo personaje - Lavinia, por ejemplo («Al final del cementerio») — o en la relación de distintos personajes —Linda y Alix (Cien botellas), Fabián y Emilio (El pájaro), «nuestro héroe» y Hojo (La sombra) - . La voz narrativa en La sombra del caminante evidencia la concepción de los personajes Hojo y Lorenzo, así como la clave de su interacción en la novela:

[Lorenzo dice] Lo que tú dices no es exactamente como tú lo dices, pero no voy a discutir contigo... Y no tengo ningún secreto, así que puedes irte a la mierda... Y Hojo, amablemente, se va a la mierda. Porque el héroe cómico, por más que se lo proponga, no puede sofocar las llamaradas del héroe trágico. No puede espantar a los bichos ni a los tipos malos. Siempre queda, por supuesto, el recurso de la burla, de instalar en el ridículo toda historia. ¿Puede ser ridículo el asesinato? ¿Y la tortura, puede? Dicho así, en abstracto...” (La sombra del caminante 2006:160).

Los héroes cómicos están regidos por lo dionisiaco y lo jovial ${ }^{6}$; los trágicos marcados por la lucha entre lo apolíneo y lo dionisiaco ${ }^{7}$. Entre los héroes cómicos encontramos a Hojo (La sombra), a Zeta (y su padre) y a la Gofia (Cien botellas), a Danilo, el adefesio y el bibliotecario de «Un loco dentro del baño», las narradoras de «El viejo, el asesino y yo», «En vísperas del accidente», y de «La última pasajera» y Cleis de «El sueño secreto de Cenicienta». Entre los trágicos, Lorenzo, Gabriela y Aimée (La sombra). La relación que se establece entre un héroe trágico y uno cómico, por ejemplo la de Lorenzo y Hojo, es

\footnotetext{
5 «Mas, puesto que los que imitan a hombres que actúan y éstos necesariamente serán esforzados o de baja calidad (los caracteres, en efectos, casi siempre se reducen a éstos solos, pues todos sobresalen, en cuanto al carácter, o por el vicio o por la virtud), o bien los hacen mejores que solemos ser nosotros, o bien peores o incluso iguales» (Aristóteles 1974: 131). «Y la misma diferencia separa a la tragedia de la comedia; ésta, en efecto, tiende a imitarlos peores, y aquélla, mejores que los hombres reales.» (132).

${ }^{6}$ Este elemento ya lo destacaba Nara Araújo en «Erizar y divertir: la poética de Ena Lucía Portela» (2001).

${ }^{7}$ Hace falta una investigación acuciosa de la importante influencia del trabajo filosófico y filológico del Friedrich Nietzsche en la narrativa porteliana, las alusiones a Así habló Zaratustra, Humano, demasiado humano - particularmente «El caminante y sus sombra»- o Más allá del bien y del mal, así como la pertinencia de tomar en cuenta los planteamientos del Nietzsche sobre el héroe de la tragedia en El nacimiento de la tragedia, ayudarían a esclarecer muchos de sus planteamientos.
} 
caracterizada por la voz narrativa como resultado «de un curioso mecanismo [...] [que] reúne en un solo fuego las llamaradas del héroe trágico y las del héroe cómico, Leo y Sagitario, el felino y el arquero, dos seres dominantes, dos empecinados, uno de frente y otro de perfil, el segundo la caricatura del primero, la burla que triunfa donde la seriedad perece, en una relación precaria, difícil, raramente viable» ( $L a$ sombra 2006:100).

Incluso los metacomentarios teóricos de las novelas sobre sí mismas oscilan entre estas fuerzas. En El pájaro: pincel y tinta china, por ejemplo, por un lado, destacando la pulsión desestabilizadora de las narraciones leemos que «La jovialidad, intuía la sacerdotisa de un modo confuso, es una condición marginal, falófora y bebedora de vino o similares. Dionisíaca se pasea, mientras la dejan (suele ser desde tiempo inmemoriales, la primera víctima de la censura), sacando la lengua y gritando obscenidades a los presentes. No se toma demasiado en serio a sí misma ni a nada.» (1999:194); mientras que también hay un constante énfasis en el lado apolíneo de las mismas: «En Cuba también vivimos personas trágicas y pesadas y densas y operáticas y medio suicidas, porque uno y nadie más que uno es el responsable de toda esa confusión. La maledicencia, de amable juego de salón, ha devenido hábito, secreción pavlovianamente previsible y hasta emblemática, antídoto contra el vacío y la muerte.» (168).

La denominación héroe en sí encierra una plurisignificación interesante que detona semánticamente a los personajes. Hombres de proezas - grandiosas o cotidianas-, semidioses, protagonistas en la jerga narrativa. Los personajes portelianos son en cierto sentido también engendros de lo inmortal y lo humano, de arquetipos literarios y de sujetos concretos - Portela se ha vanagloriado de que trasmuta anécdotas reales en literatura ${ }^{8}$ - Por lo anterior, las denominaciones y alusiones a ellos en los relatos se alternan, particularmente en las novelas: Fabián es el «loco de rostro renacentista», el hombre de la medalla y Mr, Hyde; Camila es la Sacerdotisa y la Mirada en El pájaro y en La sombra La Persona Que Busca; Bibiana es la Modelo, la Ilustre niña y Beatriz. Además se entremezclan con descripciones físicas o de sus acciones que evocan otros personajes y textos literarios. Los protagonistas portelianos son altamente intertextuales.

La narrativa porteliana, se caracteriza, en palabras de Nara Araújo, por la predominancia de un juego movilizador de referencias, cultas y populares, que concentra y complejiza el diálogo con otros

\footnotetext{
${ }^{8}$ Quizá por esto hay personajes o anécdotas que se repiten o aparecen en textos no ficcionales. Por ejemplo el personajes de Yadelis es aludido en «Alguna enfermedad muy grave» o el episodio de la mujer que apunta a la cabeza de su amante a causa de una disputa por la inminencia de una ruptura que se narra tanto en «Una extraña entre las piedras» y en Cien botellas en una pared. Sin contar, además, la diseminación de datos autobiográficos y las diversas ficcionalizaciones del yo (Genette) de Portela y el carácter autoficcional que aparece en algunas narraciones.
} 
textos (2001: 61). La intertextualidad en muchos de los cuentos y novelas es central, no sólo porque remite a la relación de copresencia entre textos ${ }^{9}$ que pueden implicar otras formas de lo que Genette denomina transtextualidad - metatextualidad, architextualidad o hipertextualidad (Palimpsestes) mediante procedimientos u otras estrategias que se vinculan con la generación de textos metaficcionales; también porque dicha relación de copresencia lo es también de implicación (de impacto recíproco), por lo que apunta a una cualidad textual que impacta en el sentido del texto ${ }^{10}$. En el caso de los personajes es fundamental cómo la intertextualidad genera una conglobación [Komplexion] de sentido, es decir, como «explosión semántica que ocurre en el contacto de los textos, de la producción de una diferencia estética y semántica» ${ }^{11}$ (2004: 17). Para ejemplificar este fundamental aspecto de la configuración de los personajes portelianos me limitaré a analizar los personajes de La sombra del caminante. He seleccionado esta novela puesto que es la que presenta el fenómeno de manera más compleja.

Antes me parece pertinente señalar que La sombra del caminante, como todo texto intertextualmente organizado, señala Lachmann, «renuncia a su identidad puntual mediante un procedimiento de referencia (deconstructivo, sumativo, reconstructivo) a otros textos. Esa relación de contacto entre texto y texto(s), cuya expresión más trivial es la de la referencia debería ser descrita como un trabajo de asimilación, trasposición y transformación de signos ajenos» (17). Esto es, todo análisis de La sombra nos demanda hacer conciencia de una doble coherencia del texto - una intratextual que garantiza su integridad inmanente y otra intertextual que crea relaciones con otros textos- (Plett 2004) ${ }^{12}$ o de un doble foco (Culler, 1993: 103) — una que llama la atención sobre la malentendida autonomía del texto, pues éste sólo adquiere significado a partir de lo anteriormente escrito; otra que

\footnotetext{
${ }^{9}$ Gérard Genette define la intertextualidad como «une relation de coprésence entre deux ou plusieurs textes, c'est-à-dire, eidétiquement et le plusieurs souvent, par la présence effective d'un texte dans un autre» (1982: 8). Parafraseo la traducción de Celia Fernández Prieto, «una relación de copresencia entre dos o más textos, es decir, eidéticamente y frecuentemente, como la presencia efectiva de un texto en otro» (1989: 10).

${ }^{10}$ Renate Lachmann en «Niveles del concepto de intertextualidad» entiende la intertextualidad como «cualidad textual que resulta de la relación implicativa [sic], garantizada por la señal de referencia, entre el fenotexto y el texto de referencia» (2004: 20).

${ }^{11}$ Para Lachman «Parece que la conglobación de sentido lograda por el fenotexto por la intertextualidad afecta al texto de referencia; que el proceso dinamizador del sentido abarca ambos textos, los cuales entran en contacto como evocante.evocado.» (2004: 20).

${ }^{12}$ Heinrich Plett plantea también en «Intertextualidades» que el intertexto (término de Michel Riffatere) «está caracterizado por atributos que van más allá de él. No está delimitado, sino des-limitado, porque sus elementos constituyentes se refieren a elementos constituyentes de otro(s) texto(s). Por lo tanto tiene una doble coherencia; una intratextual [...], y una intertextual» (énfasis del original) (2004: 53).
} 
considera a los textos previos como contribuyentes a un código que posibilita varios efectos de significado-.

Además de aclarar que la serie de alusiones, evocaciones, referencias o citas no se constriñen a la literatura, sino que provienen de la pintura, música, cine y televisión, la historia y las ciencias para desplegar un amplio abanico de la cultura tanto culta como popular. La sombra del caminante establece relaciones de intertextualidad con otras artes, para ello las verbaliza (Jenny 1976) y, por ende, realiza una transferencia de signos a otro medio (Plett 2004) ${ }^{13}$. Títulos, diálogos o citas aparecen ornamentalmente saturando el discurso; pero con mayor frecuencia lo hacen, al igual que epítetos, nombres de personajes, descripción o narración de escenas o tomas, o ecfrasis, con el objetivo de describir o caracterizar personajes.

En las caracterizaciones el solo nombre de un personaje o la referencia a su proceder - ficcional o histórico - lo construyen, ya sea a través de la sola mención del nombre o a partir de la narración de un pasaje. Por ejemplo, Hojo Pinta, que realmente se llama Howard Jones, debe su nombre de pila al egiptólogo Howard Carter (La sombra 131), y su sobrenombre, a la lúdica síntesis de las dos primeras sílabas de su nombre Ho-Jo y a la leyenda cubana que notifica a las personas sobre una superficie de pintura fresca, «OJO, ¡PINTA!» (108). Amante del protagonista de la novela, es caracterizado a partir del personaje Averell de la historieta belga Lucky Luke, creada en 1946: «medía alrededor de un metro noventa, el homúnculo del piso a la testa, y se daba tremendo aire de Averrel [sic], el mayor y más guanajo de los cuatro Dalton, los enemigos de Lucky Luke, tú sabes, los de la balada... Ah, Lucky Luke, especie de coyote...» (cursivas del original) (47-48). Los antagonistas de la historieta, los hermanos Dalton, reflejan el grado de su torpeza en su altura; Averell ${ }^{14}$ es el mayor y más sentimental de los cuatro, por lo que es, a pesar de sus esfuerzos, un mal villano. La relación de intertextualidad establecida con la historieta sintetiza lo que será Hojo Pinta a lo largo de la novela, un personaje que intenta ser un villano, en este caso un zoilo, pero que en el plano personal, aunque está perdidamente enamorado de «nuestro héroe», está imposibilitado de toda comprensión de o empatía con su amante.

\footnotetext{
13 Para Plett esta particular transferencia tendría que denominarse intermedialidad, pero al igual que para Jenny, lo que se establece es una relación intertextual y, por lo tanto, la intermedialidad es un tipo de intertextualidad.

${ }^{14}$ Resulta extremamente interesante la repetición del procedimiento, una puesta en abismo, pues los creadores de la historieta belga de Lucky Luke se inspiraron a su vez en los cuatro hermanos - Gratton, Bod, Emmet y William- que conformaban la Banda de los Dalton en el viejo oeste americano de la década de última década del siglo XIX.
} 
Ivonne Sánchez Becerril. Los personajes...

La descripción de algunos otros personajes es más compleja en tanto que no es un solo referente el que se moviliza, sino varios creando imagen a partir de la trasposición de varias evocaciones. En el capítulo octavo de la novela, Lorenzo/Gabriela se topa con una mujer de rostro desfigurado, episodio que es referido de la siguiente forma:

¿Pero qué veo...? ¿Qué coño es eso que camina, que viene para acá...? ¿Una señorita de Avignon...? [...] a la luz de la luna llena el monstruo ha dejado de ser un Picasso de la etapa expresionista, cubista, surrealista... [...] o de cualquier otra. [...] se asemeja más a un Bacon. Se asemeja, para ser más precisos, al retrato de Isabel Rawsthorne. Para ser más precisos, al recuerdo que tiene Gabriela de una reproducción vista de reojo y una sola vez del retrato de Isabel Rawsthorne. (La sombra del caminante 175-176)

Este encadenamiento (Jenny) de elementos de otros textos funciona, según Lachmann, por contaminación de señales de referencia. La superposición de alguna de las figuras de Les demoiselles d'Avignon (1907) de Pablo Picasso con la serie de retratos que Francis Bacon hiciere de su amiga y colega Isabel Rawsthorne, por ejemplo, Three studies of Isabel Rawsthorne (1966), crean la imagen de una mujer desfigurada por ácido. Aquí, como resultado de la «selección de elementos de diferentes textos de referencia» y su combinación «surgen series o capas heterogéneas; a un proceso de dispersión sigue el de una ensambladura en un nuevo complejo textual» (Lachmann, 2004: 21). De tal forma que la faz de esta mujer es fácil de imaginar, pero permanece borrosa como efecto de la superposición de imágenes y el recordatorio de la ilusión de evocar un recuerdo fiel o nítido, el recuerdo de Gabriela.

La propuesta que Ena Lucía Portela nos hace como personaje central de La sombra del caminante es particularmente desafiante en cuanto al pacto de lectura que demanda, y a la compleja comprensión de sentido que conlleva. Alternantes, Lorenzo Lafita y Gabriela Mayo comparten el rol dramatizado de «nuestro héroe» en la novela. Desde la tercera página de la historia el narrador se encarga de explicar su configuración e impartir las instrucciones de lectura pertinentes:

Entre ellos, proyectos de ciudadanos prósperos, felices y muy patrióticos, futuros hombres nuevos por ahora igualiticos a sus congéneres de todas las épocas, se encuentra Lorenzo Lafita. Y, en su mismo espacio, también se encuentra Gabriela Mayo. No se trata de dos personas distintas, ni de una sola con doble personalidad, ni de la metamorfosis de Orlando, ni del misterio de una Trinidad donde el Padre y el Hijo se hubieran confabulado para expulsar a patadas al Espíritu Santo, ni de ninguna otra cosa que hayas visto antes. Sólo están ahí, ambos. A veces se manifiesta Lorenzo y a veces Gabriela, nunca los dos a un tiempo y ninguno sabe de la existencia del otro. Por uno de esos caprichos de la vida que nadie consigue explicarse, la distinción no procede. Y no procederá, como verás, a todo lo largo del relato. Así que no te rompas la cabeza 
Ivonne Sánchez Becerril. Los personajes...

con las estalactitas y las estalagmitas de esta excepcional criatura dúplex, nuestro héroe [...] ( $\mathrm{La}$ sombra 13-14).

El recurso, según lo refiere en una entrevista la propia autora, es tomado del filme Cet obscur objet du désir (1977) de Luis Buñuel, en el que dos actrices, Ángela Molina y Carole Bouquet interpretan el papel de Conchita: «Dos mujeres bellas, pero bien distintas en su físico y en lo que éste sugiere, para dar una idea de la complejidad del personaje» («Entrevista»11). Por lo que se entiende que, conforme a esta información paratextual, la selección de esta estrategia también obedece a la intención de reflejar la complejidad del personaje concebido, y que la autora es consciente del reto que implica para el lector:

[...] el protagonista de La sombra..., a quien llamo «nuestro héroe», tiene una personalidad, hipersensible y violenta, angustiada y fuera de control, pero una sola, sin escisiones ni esquizofrenia ni nada por el estilo. Esta personalidad se manifiesta en dos formas exteriores: Lorenzo y Gabriela, quienes van alternándose a lo largo del relato. Este procedimiento para ser legible, lleva implícita la aceptación por parte del lector, o espectador, de las «reglas del juego». En caso contrario, podría penarse que el autor está loco. («Entrevista»11).

En el caso de La sombra la complejidad que quiere abordarse es la de la figura del hombre nuevo, la de los cubanos nacidos en el seno de la Revolución y el proyecto guevariano del hombre nuevo ${ }^{15}$. El establecimiento constante de la diferencia entre Lorenzo y Gabriela y el resto de los cubanos que se representan en grupo - los que se asumen como hombres nuevos-, es la puesta en evidencia de su alejamiento de la norma; no porque en verdad sean distintos, sino porque en ellos el conflicto es más intenso. El apelativo al protagonista de la novela enfatiza también esta diferencia, frente al hombre nuevo (hn) Lorenzo/Gabriela son «nuestro héroe» (nh). El primero es un ideal, «una aspiración subjetiva y no sistematizada» (Guevara, 2007: 13) del hombre del siglo XXI, un hombre libre del pecado original del capitalismo (14) y totalmente consciente «de su ser social» y, por lo tanto, de su «realización plena como criatura humana» y del «cumplimiento de su deber social» (10); el segundo, más cercano al lector por la complicidad implícita en pronombre posesivo «nuestro» y porque da cuenta de una subjetividad (aunque sea ficcional) atormentada concreta, la confrontación entre uno y otro está en el centro de la historia.

La alternancia entre Gabriela y Lorenzo permite a Portela eludir también todo reduccionismo; «nuestro héroe» representa, sí, a los cubanos fuera de las expectativas del régimen, pero también le permite resaltar la diversidad de formas en que este alejamiento es posible. Para reforzar lo anterior, los

\footnotetext{
${ }^{15}$ Para un análisis más amplio sobre el tema véanse: Ivonne Sánchez «La sombra del hombre nuevo en Ena Lucía Portela» en http://www.iiligeorgetown2010.com/2/pdf/Sanchez-Becerril.pdf, y «La metaficción en la novela cubana del Periodo Especial” en Cuadernos Americanos (143) (2013:163-189).
} 
capítulos intermedios de la novela reconstruyen, a manera de recuerdos tormentosos, la infancia de los personajes —dotándolos de diferencias-, al mismo tiempo que los describe en el presente de la narración a partir de imágenes previas, sobre todo de la cultura cubana.

Durante su infancia Gabriela Mayo tuvo que emplear aparatos de ortopedia y ortodoncia que la «aislaban en flagrante segregación» y la hacían objeto de sobrenombres — «la Bruja, el Bicho Triplefeo, el Aura Tiñosa, el Esqueleto Rumbero, la Ratona Estrambótica [...], la Tatagua, la Piojosa, Doña Basura y otros peores» (35) - y de ataques. Otro motivo de las agresiones es el racismo que impera en «la república de los niños»; en este caso, una exclusión racial por parte de las niñas negras a la intrusa, una «blanquita»: «Ellas no podían parecerse a ninguna heroína de la televisión porque todas las heroínas eran blanquitas, hasta la droga que se llama heroína es blanquita... Pero yo qué culpa iba a tener... Ellas me trataban mal, muy mal... Como si yo las hubiera sacado de África para traerlas a cortar caña...» (33) ${ }^{16}$.

Gabriela persiste como blanco de burlas y agresiones durante toda la adolescencia, pese a que le retiraron los aparatos: «había un pequeño problemita, algo con que nadie había contado: de tanta repetición nuestra muchacha se sentía esqueleto rumbero, [etc.] y otros lamentables epítetos que se habían ido agregando por el camino. Se sentía el bicho más horripilante del universo.» (80). Para la voz narrativa el complejo de inferioridad inculcado al personaje, así como una naturaleza humana que requiere constantemente de una víctima para ahuyentar el miedo propio (34), convierten a Gabriela en el objeto perfecto de toda martirización: «Fue la imposibilidad de que todos [...] no se percataran enseguida del escaso valor que la muchacha, en apariencia normal, se concedía a sí misma y no pusieran manos a la tarea de convertirle la vida en un buñuelo» (81). A Gabriela le arruinan el uniforme, llenan de inmundicia su cama, le mojan los libros, la tusan, la golpean al grado de mandarla al hospital y la acusan de ladrona, de lesbiana y difunden el rumor de que es una stinky pussy (80-85), hechos que son ignorados por el padre - un importante coronel que dirige una corporación—, su madrastra y los maestros, para quienes la muchacha es una decepción.

Si estos elementos la particularizan, la forma en que se la describe constantemente enfatiza su carácter de representación, tanto en el sentido de «Sustituir a alguien o hacer sus veces» (DRAE) a la juventud cubana, como en su papel de «hacer presente», de «referir» (DRAE) algo, de mediación de la

\footnotetext{
${ }^{16}$ Hacia el final de la novela se relatarán agresiones de los blancos hacia el personaje de Aimée Despaigne, negra: «"Una negrita cototimba, una negrita fea", había escuchado siempre de blancos y negros. Todos a su alrededor la despreciaban y la excluían. Casi pudiera decirse que la pateaban.» (199). La tematización de la perennidad del racismo en Cuba y de la reversibilidad de la misma en la novela es el objeto de estudio del artículo «Negro sobre blanco: blanco sobre negreo... Y no hace falta Malévich» de Saylín Álvarez Oquendo (2005).
} 
realidad. Físicamente, la voz narrativa siempre destaca que su rostro es confundible, impreciso, y que ha sido plasmado innumerables ocasiones por pintores:

Su rostro ni bello ni feo, es de esos que recuerdan siempre a una actriz española del Sur, amor brujo, la danza del fuego fatuo o las playas baleares, italiana del Sur, madonna dal'collo lungo [sic] y cejas negras o griega de algún sitio, hasta macedonia, montenegrina o las islas del Sur y del Levante mediterráneo, gitana tropical o el retrato de María Wilson, parecida también a la prima de Sancti Spíritus, o a la que despecha tornillos, clavos y tarugos surtidos en la ferretería de la otra cuadra, o la vecina de enfrente, o la que habita con su hijito en los altos del correo bajo un techo que se filtra. O sea cualquier mujer de su raza. Una raza sin nombre, lo mismo «sangre pura»aen el Imperio Romano, dada a persistir en sus tonalidades y facciones más allá del Latium, que «sangre quebrada» en los siglos coloniales, fundida durante las noches de júbilo en la muy leal y siempre fiel Isla de Cuba o ya desde Sevilla con su pasado judío y moro. (33-34)

La imagen manierista del cuadro Madonna dal collo lungo (ca.1534-40) de Girolamo Francesco Mazzola, Parmigianino; la colonial del Retrato de María Wilson y Mïares (1887) de Federico Martínez Matos, y la de del cuadro del modernismo pictórico cubano Gitana tropical (1929) — conocida también como «la Gioconda americana»- de Víctor Manuel García se superponen. La trasposición de las imágenes evocadas por la intertextualidad crea un rostro difuso; la belleza mediterránea de cabellos

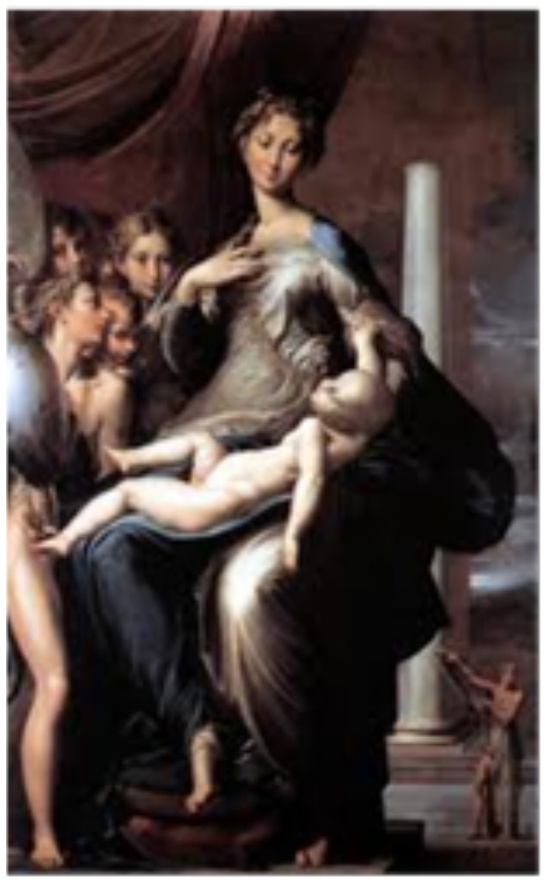

Madonna dal collo lungo Parmigianino

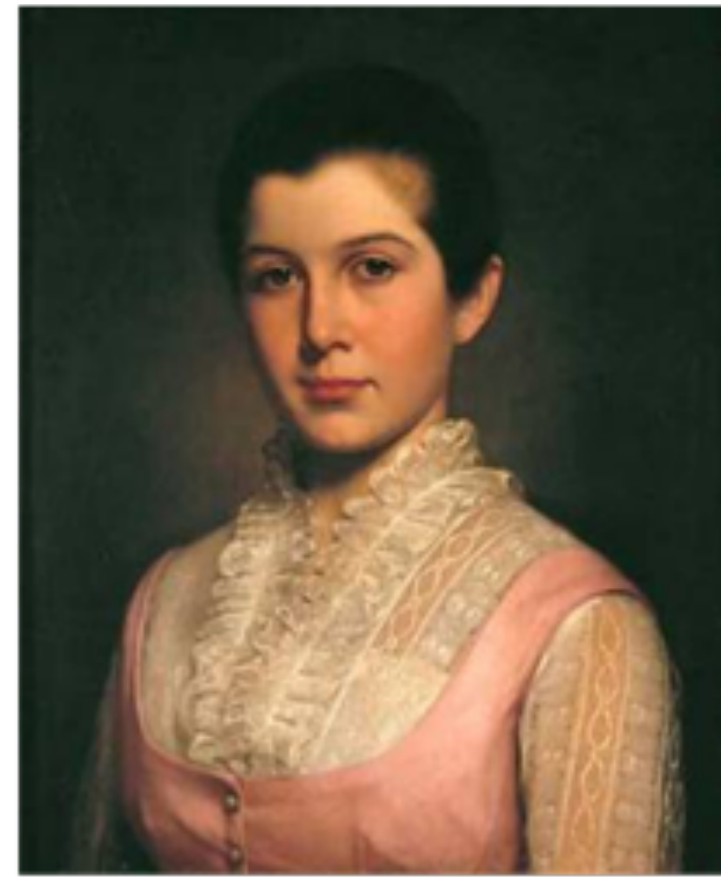

Retrato de Maria Wilson y Mijares Federico Martínez Matos

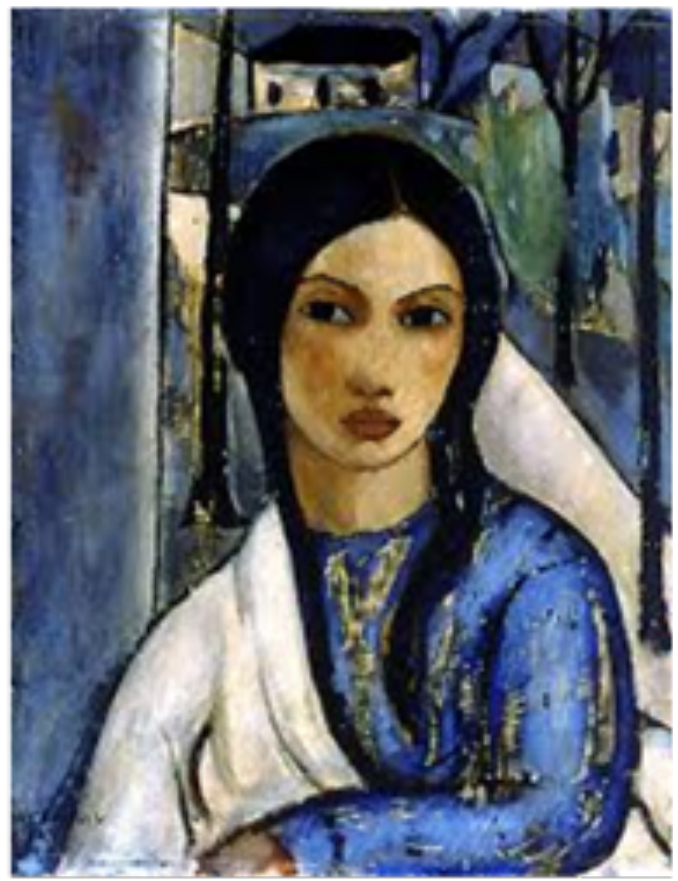

Gitana Tropical

Victor Manuel Garcia

KAMCHATKA 5 JULIO 2015 
Ivonne Sánchez Becerril. Los personajes...

castaños (también aludida en la página 116) se traspapela con la piel blanquísima y cabellos negros de la belleza ibérica (50), y termina de dislocarse en la tez morena y cabellos brunos de la mestiza (50). Gabriela es al mismo tiempo esas tres imágenes, una panorámica de los tipos de las mujeres cubanas ${ }^{17}$.

Por otro lado, durante su infancia, Lorenzo Lafita es un niño reservado, inteligente y sensible con aspiraciones artísticas. Comparte con Gabriela (y Aimée) un pasado de agresiones. Su apariencia frágil y delicada motiva que sus compañeros le digan que es homosexual — un pájaro—, y la evidenciación de su buen desempeño escolar termina de aislarlo y de convertirlo en objetivo de nuevos improperios. Tanto Lorenzo como Gabriela se encuentran imposibilitados de denunciar los maltratos, pues sus padres y sus maestros, de alguna manera, los consienten o incluso los fomentan.

Lorenzo comparte con Gabriela el tormento de los recuerdos. La voz narrativa y Hojo caracterizan a Lorenzo como un niño-viejo. La densidad de sus experiencias inscritas en el cuerpo como marcas, cicatrices, persiguen al personaje: «Nuestro héroe, $[\ldots]$ no es capaz de rechazar los asaltos de su propia memoria. En cierto sentido, él es su memoria. A los diecinueve casi veinte, es un hombre todo pretérito» (78). La imagen persiste a lo largo de la novela y podría vincularse incluso con el epígrafe que la inaugura. El poema «Viejo» ${ }^{18}$ de Roberto Friol también sintetiza la niñez y la vejez; el primer verso — «He envejecido sin saber»—, que es una toma de conciencia del tiempo, de la vida transcurrida, impacta en los dos siguientes, el epígrafe de la novela: «La pelota de colores es la pelota de la ira, /que rueda rencorosa por la playa»; la imagen infantil que evoca la pelota de colores que trastoca por la perspectiva de la vejez, el recuerdo, que debería ser alegre, se torna amargo. En La sombra Lorenzo es descrito como un «Lao-tsé, viejo y niño a la vez, un cincuentón, honorable y rígido en el estilo de Marco Junio Bruto» (104) y presentado como, ya se ha señalado, «héroe trágico».

El papel de la intertextualidad en la configuración de Lorenzo actúa de forma distinta, pues sólo la escultura del Perseo de Cellini es constitutiva, mientras que Strange Case of Dr. Jekyll and Mr. Hyde (1886) de Robert Louis Stevenson entre otros referentes son empleados en comparaciones momentáneas. Hacia la mitad de la novela Hojo, que asume por un momento la voz narrativa, hace una comparación entre la silueta de Lorenzo y la del Perseo con la testa di Medusa o Perseo del Cellini (ca. 1545-1554) de Benvenuto Cellini. Por mediación de la escultura florentina Portela establece un símil de belleza: «A pesar de su breve estatura, o quizás gracias a ella, esta otra silueta era la de un adolescente

\footnotetext{
${ }^{17}$ El referente de las mujeres negras en la isla estaría representado por el personaje de Aimée Despaigne.

${ }^{18}$ Interesante que el poema a su vez tenga un epígrafe que reafirma la gravedad de la perspectiva de la voz lírica del poema y de la vejez metafórica del personaje de Portela, tres versos del poeta español Jorge Manrique, citados (equívocamente) de memoria: «todo se vuelve graveza/ al llegar al arrabal [debería decir: «cuando llega al arrabal»]/ de senectud» (1999: 23).
} 
Ivonne Sánchez Becerril. Los personajes...

perfecto, magnífico entre todos los que deambulaban [...] por las utopías sensuales del individuo alto y media humanidad» (100). Si Gabriela representa la belleza femenina; Lorenzo, la perfección masculina. La voz narrativa deja en claro a plena vista no hay diferencia o anormalidad alguna entre «nuestro héroe» y el «resto de sus congéneres», lo cual, hace terrible el destino del personaje.

\section{De la configuración de los personajes a la hipótesis sustancial de la naturaleza del mundo}

Puesto que en La sombra del caminante el crimen define a los personajes considero pertinente analizar cómo la pertenencia de «nuestro héroe» a la tradición literaria de los «pistoleros casuales» lo define y lo vincula directamente con esa hipótesis sustancial del mundo que pervive como trasfondo de las narraciones portelianas, y que en esta, segunda novela de la escritora, se tematiza y desarrolla con más amplitud. Asimismo, la caracterización de Lorenzo/Gabriela como «pistoleros de la casualidad» detona semánticamente la totalidad de la obra.

El doble asesinato que «nuestro héroe» perpetra en el primer capítulo es caracterizado como producto de un estallido en el personaje producido por el apelativo «blanquita». La particularidad de dicha explosión es que deja libre un pasado latente, tanto ficcional como literario. Por un lado, la «diminuta ráfaga contra lo reseco del tapiz de hierbas, muros, tabiques, alambradas [...] Una escueta fracción. Se acaba de encender la mecha y algo va a explotar. Pero nadie lo advierte porque nadie mira.» (La sombra 17) alude a sendos pasados de agresiones, ya explicitados, de Lorenzo y Gabriela; por otro, la memoria latente desatada está vinculada a la memoria literaria de aquellos personajes que se convierten en «pistoleros de la casualidad». Esta memoria de la tradición literaria que la voz narrativa evoca en el personaje actúa como un subconsciente narrativo, como predestinación de la trama: «De manera que - piensa Lorenzo - el artefacto [la pistola] se va a acomodar de lo mejor en mi mano hasta subir a la temperatura de lo vivo y formar parte del cuerpo. La más poderos. Más que una prótesis, la memoria latente de Mario, el de Torre di Venere, o de Mersault [sic] en una playa africana. De tantos y tantos pistoleros casuales.» (La sombra 15).

La alusión a El extranjero se reafirma cuando más tarde en el discurrir de la posibilidad de esclarecer las motivaciones del homicidio se establece el paralelismo del sol ${ }^{19}$ como causa: «iSe puede hablar de "accidente"? En cierto sentido sí. Un caso de pérdida momentánea de la razón, un impulso

\footnotetext{
${ }^{19}$ La presencia del sol es un elemento predominante en el capítulo primero de La sombra. La narración se inaugura con la descripción del campo de tiro a partir de los efectos de la luz sobre el paisaje y se establece la condición de un verano perenne: «Estamos a finales de octubre y es verano, siempre verano en la zona tórrida» (11).
} 
controlable... Este sol hijoeputa, que le derrite los sesos a la gente...» (24). Lo que hermana a Mario y Meursault con «nuestro héroe» es el crimen y la peculiaridad de sus contextos, que aunque muy distintos los unos del otro convergen pertinentemente para la conglobación de sentido en La sombra.

La atmósfera de comportamientos desmedidos por una moral y un nacionalismo exaltados, así como por cierta xenofobia que empañan constantemente las vacaciones del narrador y su familia en Mario y el mago, de Thomas Mann; la fascinación y rechazo que ejerce la figura del Cavalieri Cipola, y la naturaleza de su espectáculo son elementos trastocados por la implicación que provoca la referencia intertextual. El espectáculo del Cavalieri Cipola consiste en la puesta en escena de las posibilidades y límites del libre albedrío y la voluntad, pues Cipola les pone en prueba con su sometimiento en una serie de ejercicios de hipnosis. Cipola explica así el fenómeno a su público:

En el resultado final su oposición no cambiará un ápice. Existe el libre albedrío, como existe también la voluntad; pero una libertad absoluta no existe, pues una voluntad que pretende la libertad absoluta se contradice y cae en el vacío. Libre es usted de escoger o no escoger una carta. Pero si usted elige escogerá la carta prescrita y esto con tanta mayor seguridad cuanto más arbitraria intenta ser su elección. (Mann 1968:98)

Mario dispara a Cipola ${ }^{20}$ porque toma conciencia de que éste último lo ha manipulado en estado hipnótico para que le besara. Aunque una de las premisas que subyacen en la novela es la supeditación del destino de los sujetos a la lógica nacional, de ahí que se subraye constantemente su predestinación; «nuestro héroe» nunca concibe su vida atormentada en relación al contexto en el que ha crecido. La descarga de Lorenzo/Gabriela está en el borde de la conciencia y el inconsciente. Meursault, el protagonista de El extranjero de Camus, en cambio, dispara consciente y gratuitamente afectado por la luz.

La complejidad de sentido lograda a partir de la evocación de la novela de Mann y la de Camus con relación a un solo elemento nodal — una acción que los describe - de La sombra es producto de la superposición y movilización de dos hipótesis (Pavel 2005), si no opuestas, muy diferentes, que paradójicamente convergen en cuestionamientos que les son centrales. Si bien «nuestro héroe», a

\footnotetext{
${ }^{20}$ Aventurando una hipótesis de lectura adyacente, la figura de Cipola sí tendría una correspondencia en el contexto asfixiante del protagonista porteliano, pues su poder radica en su manejo del discurso; a partir de un fascinante manejo del lenguaje doblega las voluntades de los participantes voluntarios mientras el público, entre maravillado y temeroso, consiente y solicita las demostraciones de poder. La figura de Fidel Castro, a diferencia de otros narradores cubanos de los noventa, en Portela nunca es representada explícitamente, aunque siempre está presente desde su ausencia, como en sordina. En El pájaro:pincel y tinta china, por ejemplo, el Dr. Schilling — médico que dirige la institución en la que Camila es ingresada - ha sido leída como la representación en clave de Castro.
} 
Ivonne Sánchez Becerril. Los personajes...

diferencia de Meursault, intenta «jugar el juego» ${ }^{21}$-intentando de distintas formas asimilarse一, continuamente se ve imposibilitada su participación. Tanto Lorenzo/Gabriela como Meursault son condenados por el crimen, más que el asesinato, la diferencia.

He aquí el planteamiento en común de ambas novelas - y en muchas de las narraciones portelianas-. Extranjero de sí mismo, de su contexto, Meursault se deja llevar por la serie de circunstancias que siente ajenas, la muerte de su madre, las villanías de Raymond, la propuesta de matrimonio de Marie, la disputa con el grupo de árabes en la playa, el asesinato, el juicio. La confrontación que representa Meursault para el orden social —el juego - se evidencia en el juicio; por un lado, su destino se revela como ajeno: «Todo se desarrollaba sin mi intervención. Mi suerte se definía sin pedirme la [sic] opinión» (Camus 2002: 127-128); por otro, su culpabilidad no se juzga por el hecho en sí del asesinato, sino por la postulación de una mente, un «corazón de criminal» (124) ante el cual todo proceder es recriminable: «Yo escuchaba y oía que se me juzgaba inteligente. Pero no comprendía bien cómo las cualidades de un hombre común podían convertirse en cargos aplastantes contra un culpable.» (130). El extranjero cuestiona implícitamente sobre la concepción misma del crimen, y por ende, la diferencie entre el hombre común y el criminal.

Lorenzo y Gabriela son, como Meursault, hombres comunes criminalizados no por un delito, sino por la perturbación que causa el reconocimiento del carácter intrínseco a los sujetos de las diferencias que ellos evidencian. Emilio U suscribe esta idea en su diario de escritura citando: «Otra de Jean Rostand: "Tal vez queremos castigar a este hombre, más que por su crimen, por el desconcierto en que nos coloca al o diferenciarse de nosotros por su crimen”.» (las cursivas son del original) (La sombra 198). La caracterización que da la voz narrativa a Mario, Meursault y «nuestro héroe» como pistoleros casuales otorga una carga atenuante a sendos asesinatos vinculada al cuestionamiento de la noción sociohistórica del crimen que hace la novela. Hay, en La sombra del caminante, una premisa del crimen como resultado de sinergia social y, por ende, también como síntoma de una enfermedad cultural. Lo que sucede a los protagonistas de Mario y el mago, de El extranjero y de La sombra es como declara en el juicio Céleste, el dueño del restaurante en el que es cliente frecuente Meursault, «es una desgracia. Todo el mundo sabe qué es una desgracia. Lo deja a uno sin defensa. Y bien: para mí es una desgracia» (Camus 2002: 119). El resultado abrupto, pero inevitable, de la catástrofe que deja el huracán del progreso

\footnotetext{
${ }^{21}$ En un prólogo a la novela Camus destaca: «Je voulais dire seulement que le héros du livre es condamné parce qu’il ne joue pas le jeu. En ce sens, il est étranger a à la société où il vit, il erre, en marge, dans les faubourgs de la vie privée, solitaire, sensuelle. [...] il refuse de mentir. Mentir ce n'est pas seulement dire ce qui n'est pas. C'est aussi, c'est surtout, dire plus que ce qui est et, en ce que qui concerne le cœur humain, dire plus qu'on ne sent.» (Camus 1988:VII).
} 
Ivonne Sánchez Becerril. Los personajes...

- concepto esencial de las sociedades modernas, capitalista o socialista - de su paso en la historia (Benjamin 2007: 69-70).

Lo anterior pone en evidencia la distinción entre dos fenómenos, la criminalización y el crimen en sí. Al crimen, en tanto delito, le corresponde una sanción judicial; la criminalización en los relatos portelianos es un proceso que castiga la diferencia, la ruptura o ignorancia de una serie de normas o códigos de conducta implícitos, como una ofensa a la Sociedad como un todo. A Meursault como a «nuestro héroe» es el proceso de criminalización y no el jurídico el que los conduce a la muerte. La mención aparentemente gratuita de Vigilar y castigar de Michel Foucault entre los papeles de Hojo Pinta (La sombra 119) establece una relación intertextual que busca redondear y complejizar la problematización de la noción de crimen. Foucault distingue que,

Puesto que bajo el nombre de crímenes o delitos son perseguidos no el cuerpo de sujetos concretos sino sujetos jurídicos, un delito («objeto jurídico»), por menor que sea, ataca a la sociedad entera. Se juzgan «objetos jurídicos», pero se penalizan: pasiones, instintos, anomalías, achaques, inadaptaciones, efectos de medio o de herencia; se castigan las agresiones, pero a través de ellas las agresividades; las violaciones, pero a la vez las perversiones; los asesinatos, que también son pulsiones y deseo [...] no son ellos los juzgados [...] si los invocamos es para explicar hechos que hay que juzgar y para determinar hasta qué punto se hallaba implicada en el delito la voluntad del sujeto [...]. Juzgadas también por el juego de todas esas nociones que han circulado entre medicina y jurisprudencia desde el siglo XIX (los «monstruos» de la época de Georget, las «anomalías psíquicas» de la circular Chaumié, los «perversos» y los «inadaptados» de los dictámenes periciales contemporáneos) que, con el pretexto de explicar un acto, son modos de calificar a un individuo. (Foucault 2009:27)

La reflexión que suscita La sombra es compleja. La criminalización traspasa al sujeto, lo trasciende; lo conmina a asimilarse o a excluirse para contribuir o no entorpecer el orden social. Las fuerzas simultáneas de la dinámica social se ejercen contradictorias sobre los individuos; la detonación de las tensiones acumuladas es el delito. El crimen es un accidente, una desgracia, un síntoma.

En una de las entradas del diario de Emilio U se alude al síndrome de amok — «Muchas ganas de correo y correr, amok [aquí una línea tachada a mano]» (corchetes del original) (La sombra 195)—, un síndrome vinculado a la cultura que consiste en «un episodio disociativo caracterizado por un periodo taciturno seguido de un brote violento, agresivo, o un comportamiento homicida» (APA 2000: 899) ${ }^{22}$. La

\footnotetext{
22 «A dissociative episode characterized by a period of brooding followed by an outburst of violent aggressive, or homicidal behavior» (899) (La traducción es mía).
} 
mención de dicho síndrome da nombre a una sensación que brota en Emilio, pero, puesto que las entradas del diario intercalan reflexiones sobre la escritura de su novela como de su vida cotidiana en París, su pertinencia para explicar tanto el doble homicidio que inaugura la novela como la muerte del propio Emilio U se hace evidente con el desarrollo de las acciones narradas. En Lorenzo/Gabriela el brote del síndrome — «La chispa [...] Se acaba de encender la mecha y algo va a explotar» (La sombra 17) - resulta en el asesinato, la huída y el suicidio; en Emilio, en la necesidad de correr y provocarse la muerte: «Vuelven las ganas de correr. Bajo la lluvia, correr. Cruzar la calle sin mirar ni por un instante la luz equivocada del semáforo ni tampoco los carros, los tres pilares básicos de la industria automovilística francesa...» (200).

Si el síndrome de amok incorpora el tratamiento del crimen como síntoma de una enfermedad cultural, la referencia intertextual del Crimen y castigo de Fiodor Dostoyevski, de El proceso de Franz Kafka y de El extraño caso del Dr. Jekyll y el Sr. Hyde de Robert Louis Stevenson revelan el martirio y el vértigo producido por el crimen en la psique de «nuestro héroe». En ese sentido, La sombra, como rezan los versos de Borges ${ }^{23}$ en el epígrafe del capítulo décimo, y final, de la novela, busca ofrecer explicaciones, teorías, noticias auténticas y sorprendentes del yo y su naturaleza.

El recorrido de «nuestro héroe» es esta exploración del yo ante el crimen: la somatización del crimen como le sucede a Raskólnikov en la novela de Dostoyevski; la asfixiante, consumidora e invisible acción persecutoria de la ley e innacesibilidad de la justicia como en la novela kafkiana; como un descenso al inframundo, al infierno, o en este caso, por las diferentes esferas de La Habana profunda y los condenados al castigo de la exclusión, a la manera dantesca del «Infierno» de la Divina comedia. Pero también un camino forzado a la soledad y la errancia como única vía de búsqueda de sí mismo, de disolver la ambivalencia para ser libre, como el caminante de Fiedrich Nietzsche, como Mersault la víspera de su ejecución.

\section{Conclusión}

Las constantes en los personajes señalados al inicio de este trabajo se reafirman, complejizan y profundizan a través de las estrategias empleadas en su construcción en una intensa relación con los planteamientos específicos de cada texto y de la poética porteliana. De tal forma que, su juventud, sus

\footnotetext{
${ }^{23}$ En la página 213 aparecen como epígrafe los siguientes versos del Segundo de los «Two English Poems» de Jorge Luis Borges: «I offer you explanatios of yourself, / theories about yourself, / authentic and surprising news of yourself»
} 
diferencias, sus particularidades o su marginalidad no constituyen simplemente rasgos sino que apuntan a problemáticas que son resemantizadas a partir de sus periplos textuales y dimensiones intertextuales que ponen en relieve contextos históricos y literarios. La efectividad y centralidad de los personajes portelianos en su narrativa estriba en el estratégico contrapeso entre la densidad de significación y la evidenciación de sus estatus de personajes. Estos personajes sui generis, directrices de la narrativa porteliana, son el punto de mayor equilibrio entre el despliegue de estrategias narrativas y el mundo narrado, por lo que la reflexión que provocan en el lector es la vía más efectiva de acceder a la «hipótesis sustancial sobre la naturaleza y organización de mundo» que nos plantea Ena Lucía Portela. 
Ivonne Sánchez Becerril. Los personajes...

\section{Bibliografía citada}

American Psychiatric Association (2000). Diagnostic and Statistical Manual of Mental Disorders (4. ${ }^{\text {a }}$ ed.). Washington: APA.

Araújo, Nara. "Erizar y divertir: La poética de Ena Lucía Portela”. En Cuban Studies 32 (2001): 55-73.

Aristóteles (1999). Ars Poética (edición trilingüe). Madrid: Gredos.

Bauman, Zygmunt (2006). Ética posmoderna (2. ${ }^{\mathrm{a}}$ ed.). México: Siglo XXI.

Benjamin, Walter (2007). "Sobre el concepto de la historia". Conceptos de filosofía de la historia. La Plata: Terramar: 65-76.

Bobes, Velia Cecilia (2000). Los laberintos de la imaginación. Repertorios simbólicos, identidades y actores del cambio social en Cuba. México: COLMEX.

Campuzano, Luisa (2004). Las muchachas de La Habana no tienen temor de Dios... Escritoras cubanas (s.XVII-XXI). La Habana: Ediciones Unión.

Camus, Albert (2002). El extranjero. Del Carril, Bonifacio (trad.). Buenos Aires: Emecé.

Camus, Albert (1988). L'étranger. Davidson, Ray (ed.). London: Routledge.

Casamayor-Cisneros, Odette. "Guanajerías pos-soviéticas: apuntes ético-estéticos en la narrativa de Ena Lucía Portela”. La Gaceta de Cuba 6 (2009): 3-7.

Casamayor-Cisneros, Odette (2013). Utopía, distopía e ingravidez. Reconfiguraciones cosmológicas en la narrativa postsoviética cubana. Madrid: Iberoamericana / Vevuert.

Culler, Jonathan (1993). The Persuit of Signs. Ithaca: Cornell University Press.

Fornet, Jorge (2006). Los nuevos paradigmas. Prólogo narrativo al siglo XXI. La Habana: Letras Cubanas.

Foucault, Michel (2009). Vigilar y castigar (2. ${ }^{\mathrm{a}}$ ed.). México: Siglo XXI.

Friol, Roberto (1999). Zodiakos. La Habana: Unión / Letras cubanas.

Genette, Gérard [1989 (1982)]. Palimpsestos/Palimpsestes. Madrid: Taurus/Paris: Seuil. 
Ivonne Sánchez Becerril. Los personajes...

Guevara, Ernesto (2007). "El socialismo y el hombre en Cuba". El socialismo y el hombre nuevo. México: Siglo XXI: 3-17.

Jenny, Laurent. “La stratégie de la forme”. Poétique 26 (1976) : 257-281.

Lachmann, Renate (2004). "Niveles del concepto de intertextualidad". Intertextualität 1. La Habana: Criterios / Casa de las Américas / UNEAC: 15-24.

Mann, Thomas (1968). "Mario y el mago". Obras completas. Novelas. Barcelona: Plaza y Janés: 61-124.

Pavel, Thomas (2005). Representar la existencia. El pensamiento de la novela. Roas Deus, David (trad.). Barcelona: Crítica.

Plett, Heinrich (2004). "Intertextualidades”. Intertextualität 1. La Habana: Criterios / Casa de las Américas / UNEAC: 50-84.

Portela, Ena Lucía (1995). “Últimas conquistas de la catapulta fría”. Redonet, Salvador (selección, prólogo y notas). Doce nudos en el pañuelo. Mérido: Mucoglifo / Dirección Sectorial de Literatura CONAT: 9-15.

Portela, Ena Lucía (1999a). El pájaro: pincel y tinta china. Barcelona: Casiopea

Portela, Ena Lucía (1999b). Una extraña entre las piedras. La Habana: Letras cubanas

Portela, Ena Lucía (1999c). “Sombrío despertar del avestruz”. Garrandés, Alberto (comp.). Aire de luz. Cuentos cubanos de siglo XX. La Habana: Letras cubanas: 497-505.

Portela, Ena Lucía (2002). Cien botellas en una pared. La Habana: Unión

Portela, Ena Lucía (2006). La sombra del caminante. Kailas: Madrid

Portela, Ena Lucía (2009). El viejo, el asesino, yo y otros cuentos. López, Iraida (eda.). Doral: Stockcero.

Real Academia Española de la Lengua (2001). Diccionario de la Real Academia Española de la Lengua $\left(22^{\mathrm{a}} \mathrm{ed}\right)$.

Rufinelli, Jorge. "Ena Lucía Portela: La Habana, 1972”. Nuevo Texto Crítico vol. 21, 41-42 (2008): 7-20. 
Ivonne Sánchez Becerril. Los personajes...

Santiesteban-Prats, Ángel. “La generación extraviada”. Encuentro de la cultura cubana 51/52 (2009): 3-9.

Žižek, Slavoj (2008). Violence. Six Sideways Reflexions. London: Profile Books. 